\title{
Usos dos pretéritos perfeito, imperfeito e mais-que- perfeito em contextos de variação: contribuições para o ensino de Língua Portuguesa
}

Márluce Coan"

Raquel Meister Ko. Freitag***

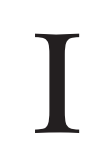

ntrodução

O paradigma verbal do Português, especificamente da variedade falada no Brasil, vem passando por transformações que em muito o distanciam do que é prescrito pelos compêndios gramaticais, o que pode levar a dúvidas em aprendizes, além de distanciar ainda mais o vernáculo da prescrição gramatical, a ponto de parecerem duas línguas totalmente distantes e diferentes. Neste estudo, mostramos o funcionamento de formas verbais utilizadas para expressão do tempo passado, mais especificamente, as formas de pretérito mais-que-perfeito (simples e composto), pretérito perfeito, pretérito imperfeito (simples e perifrástico), com base nos resultados de Coan (1997) e Freitag (2007). Valendo-nos dos pressupostos da Sociolinguística Variacionista (Labov, 1972; 1978; 1994; 2001), investigamos trinta e seis entrevistas realizadas em Florianópolis, cada uma com cerca de uma hora de duração, do corpus do Projeto VARSUL (Variação Linguística Urbana na Região Sul). Os dados foram submetidos à análise quantitativa por meio de modelo logístico de análise de dados, possibilitando que o fenômeno da variação - correlação usos linguísticos/estrutura social - seja abordado estatisticamente. A análise dos dados segue a linha funcionalista givoniana, para quem "o estudo sistemático e quantificado da sintaxe no discurso serve como uma

\footnotetext{
* Professora da Universidade Federal do Ceará.

** Professora da Universidade Federal de Sergipe.
} 
transição necessária e natural para relacionar a língua e a comunicação com os processos cognitivos” (Givón, 1984, p.11).

Com este estudo, buscamos fornecer subsídios acerca do funcionamento da expressão do tempo passado por meio de formas verbais, a fim de complementar e subsidiar a produção de livros didáticos e gramáticas pedagógicas, especialmente aqueles destinados ao ensino de Português como língua estrangeira. Falantes de línguas anglo-germânicas não possuem em sua gramática uma forma para pretérito imperfeito do indicativo e o past progressive tem usos muito restritos, especialmente quanto à dinamicidade dos predicados; falantes de línguas eslavas codificam as diferenças aspectuais diretamente na morfologia verbal. Sistemas temporais como os de Kamba, Mabuiag, Bamileke-Dschang, Bamileke-Ngyemboom, Kiksht, conforme Comrie (1990), apresentam mais de duas formas para fazer referência a subdivisões no passado. O russo pode ser arrolado como um exemplo de língua cujos tempos verbais são predominantemente absolutos, nesse caso, um elemento inserido no contexto discursivo (por exemplo, um advérbio como o já) é que possibilita a interpretação de uma situação como anterior a outra, mesmo tendo sido codificada depois, como em Kolja priexal; Masa uze uexala./Kolja chegou; Masa já SAIU. (Comrie, 1990, p.68).

Para cumprirmos nosso objetivo, primeiramente, apresentamos o domínio funcional complexo Tempo-Aspecto-Modalidade, que está, em maior ou menor grau (a depender do contexto), saliente nas categorias verbais. No segundo momento, apresentamos o funcionamento variável do pretérito mais-que-perfeito e pretérito imperfeito na amostra de fala analisada. Ao final, tecemos considerações acerca da implicação da diversidade de usos das formas verbais de passado no ensino de Língua Portuguesa.

\section{O domínio funcional complexo Tempo-Aspecto-Modalidade}

Domínio funcional é o escopo de atuação de uma dada função desempenhada por uma (ou mais) dada forma em uma dada língua (Givón, 1984). Componentes universais das línguas, tempo, aspecto e modalidade são categorias que interagem entre si, formando um domínio funcional complexo (Givón, 1984; 1995). A complexidade desse domínio funcional decorre do fato de as fronteiras entre cada um dos subcomponentes nem sempre serem claras e precisas, impossibilitando a dissociação, na prática, de um componente do outro.

Retomemos a discussão proposta em Coan, Back, Reis e Freitag (2006). A noção de tempo refere-se à ordenação de eventos 
(experiências) sob a forma de pontos e intervalos em uma sequência. É uma noção que se apóia em Reichenbach (1947), para quem os tempos verbais são determinados pela ordenação do momento da situação em relação ao momento de referência e ao momento do ato de fala de um dado enunciado. Denomine-se momento da fala ao momento da enunciação. A partir da definição desse ponto, é possível estabelecer três relações temporais básicas: antes do momento de fala, simultâneo ao momento da fala e posterior ao momento da fala. A fixação de apenas um momento fornece somente três relações temporais. Na proposta de Reichenbach (1947), a expressão do tempo verbal está relacionada a mais dois parâmetros, cujas posições podem ser determinadas a partir do momento da fala: o momento da situação e o momento da referência. O momento da situação é o momento em que a situação ocorre; o momento da referência é um momento que serve como parâmetro - uma referência temporal - para determinar o momento da situação, estabelecido em relação ao momento da fala. Quando não há referência temporal contextualmente explícita, o momento da fala torna-se o momento da referência.

Enquanto a categoria gramatical tempo é responsável pela constituição temporal externa, uma vez que estabelece relações com o momento de fala e pontos de referência, a categoria gramatical aspecto costuma designar os diferentes modos de perceber a constituição temporal interna de uma situação (Comrie, 1976). A noção de aspecto envolve a ideia de configuração interna do tempo em eventos (estado inicial, medial, final; evento apresentado como perfectivo/fechado ou imperfectivo; aberto, entre outras possibilidades). $\mathrm{O}$ aspecto perfectivo, a cuja constituição interna não interessa referir, é caracterizado pela perspectiva global da situação, que é expressa fechada, formando uma unidade ou conjunto. Já o aspecto imperfectivo expressa diferentes nuanças da temporalidade interna: que se desenrola (cursivo), ou selecionando fases do tempo interno (inicial, medial, final), ou expressando estados resultativos, dentre outras possibilidades. $\mathrm{O}$ aspecto imperfectivo não identifica os pontos inicial ou final da situação, mas focaliza o seu desenvolvimento, em contraponto ao perfectivo, que enfatiza os pontos inicial ou final.

Assim, embora o "tempo passado" canonicamente esteja dividido em pretérito perfeito, imperfeito, mais-que-perfeito e o futuro do pretérito, essas relações não são necessariamente temporais. A categoria tempo interage fortemente com a categoria aspecto, embora seja esta 
última preterida nas prescrições normativas, e também com a modalidade, como delineado por Givón (1984). ${ }^{1}$

\section{Pretéritos perfeito, imperfeito e mais-que-perfeito em contextos de variação}

A maioria das gramáticas dos séculos XX (Pereira, 1923; Said Ali, 1964; Luft, 1976; Almeida, 1982; Rocha Lima, 1986; Nunes, 1989; Cunha \& Cintra, 2001²) expõe que, em sua forma simples ou em sua forma composta, o pretérito mais-que-perfeito indica uma ação que ocorreu antes de outra ação passada, exemplificando o uso mediante paradigmas de conjugação. Essa definição focaliza, internamente, apenas a noção de tempo expressa pela forma verbal: uma situação passada ocorrida antes de outra também passada, o que não parece ser suficiente para explicitar o funcionamento do pretérito mais-que-perfeito e para diferenciá-lo de outras formas verbais que também expressam passado, como o perfeito e o imperfeito. As gramáticas de base normativa, anteriormente citadas, pouco dizem, também, sobre o pretérito perfeito simples: apresentam esse tempo verbal como forma de codificação de um tempo passado em relação ao tempo de fala e exemplificam-no mediante paradigmas de conjugação.

O mesmo pode-se dizer do pretérito imperfeito; embora seja um tempo verbal altamente recorrente na língua, tradicionalmente, costuma ser associado à função de codificar 'passado inacabado'. A forma, entretanto, desempenha várias funções, inclusive em domínios funcionais prototípicos de outras formas verbais, como o futuro do pretérito e o pretérito imperfeito do subjuntivo. Os estudos deste tempo verbal, no

\footnotetext{
${ }^{1}$ A modalidade costuma ser definida como a gramaticalização das atitudes do falante em relação ao conteúdo proposicional. É possível reconhecer uma categoria gramatical (a modalidade) que é semelhante ao tempo, aspecto, número e gênero. Givón (1995) divide a modalidade em epistêmica, que está relacionada à verdade, crença, probabilidade, certeza e evidência (realidade/factualidade); ou deôntica, relacionada à preferência, desejo, intenção, habilidade, obrigação e manipulação. A noção de realidade/factualidade remete à existência factual em algum tempo real (verdadeiro), ou a não-existência em um tempo real (falso) ou, ainda, à existência potencial em um tempo (possível), o que configura as possibilidades: i) a situação é fato; ii) a situação não é fato, mas tem grande probabilidade de sê-lo; e iii) a situação não é fato, e nunca vai sê-lo. Nos tempos sob análise - e nas funções delimitadas -, o valor de modalidade não é saliente.

${ }^{2}$ Cunha e Cintra (2001, p. 456-458), além de focalizarem o pretérito mais-queperfeito como a forma de codificação de um passado anterior a outro passado, apresentam outros usos desse pretérito: a) denota um fato vagamente situado no passado, nesse caso, há o uso do pretérito mais-que-perfeito pelo pretérito perfeito, e um fato passado em relação ao momento presente, quando se deseja atenuar uma afirmação ou um pedido; b) é utilizado em lugar do futuro do pretérito e do pretérito imperfeito do subjuntivo, na linguagem literária, e c) é usado em frases exclamativas.
} 
Português, costumam ser realizados em contraponto ao pretérito perfeito (Rodrigues et al., 1996), sem abordar as suas especificidades e atuação em outros domínios funcionais, indicando uma lacuna nos estudos. Vejamos, a seguir, resultados de análises que captam os contextos de variação das formas.

\section{Uso variável dos pretéritos mais-que-perfeito e perfeito: motivações em competição}

Nesta seção, visamos a demonstrar que os usos variáveis dos pretéritos mais-que-perfeito composto (conforme (01)) e perfeito simples (conforme (02)), na codificação da anterioridade a um ponto de referência passado, estão condicionados por fatores linguísticos: semântico-discursivos e morfossintáticos. Foram analisadas 576 ocorrências; consideramos, igualmente, os casos de pretérito mais-que-perfeito com o auxiliar tinha e aqueles com havia. A grande maioria das ocorrências do corpus aparece com o auxiliar tinha. O pretérito mais-que-perfeito simples não foi utilizado como variante porque apenas duas formas foram encontradas e com valor de projeção futura (TOMARA que eu esteja enganado! - FLP 21, L666).

(01) ...ela foi lá falar com a Telma que TINHA DADO positivo, que TINHA FICADO bem azulzinho. (FLP 20, L1204) ${ }^{3}$

-Momento do Evento-Momento de Referência-Momento de Fala'!

TINHA DADO

foi...falar

\section{TINHA FICADO}

(02) ... ela falou que FIZERAM ${ }^{4}$ a reação com o sangue e DEU positivo (FLP 20, L1206)

-Momento do Evento-Momento de Referência -Momento de Fala'!

FIZERAM

DEU falou

\footnotetext{
${ }^{3}$ No decorrer desta pesquisa, utilizamos alguns códigos adotados pelo Projeto VARSUL para especificar entrevistas, tais como: cidade (FLP - Florianópolis), número da entrevista (20) e número da linha (1204). Todos os dados aqui considerados foram retirados de entrevistas do banco de dados do Projeto VARSUL.

${ }^{4}$ Há neutralização na codificação da terceira pessoa do plural do pretérito maisque-perfeito simples e do pretérito perfeito simples. Consideramos fizeram como exemplo de $3^{\underline{a}}$ pessoa do plural do pretérito perfeito simples, por não encontrarmos, no corpus coletado, nenhum outro dado de pretérito mais-que-perfeito simples para codificar um passado anterior a outro passado.
} 
Em (01), podemos intercambiar tinha dado e tinha ficado por deu e ficou. Em (02), as formas fizeram e deu podem ser substituídas pelas formas tinham feito e tinha dado. Isso comprova que os pretéritos mais-queperfeito composto e perfeito simples são variantes de uma mesma variável: codificação de uma situação passada anterior a outra passada, o ponto de referência, representado, nos exemplos anteriores, por foi falar e falou. De acordo com Labov (1978, p. 02), “dois enunciados que se referem ao mesmo estado de coisas têm o mesmo significado representacional ou o mesmo valor de verdade”, ou seja, são variantes linguísticas. Interessa-nos, agora, analisar os contextos que favorecem uma ou outra forma.

\begin{tabular}{|c|c|}
\hline Gmal de tear & 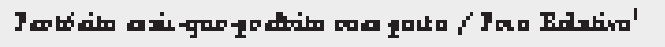 \\
\hline Jacldin a then 교 & 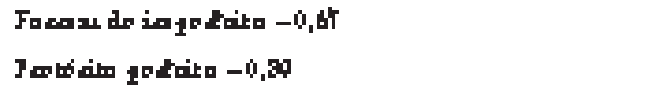 \\
\hline I 10 de & 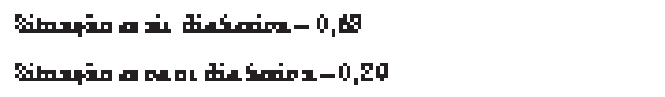 \\
\hline 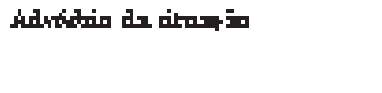 & 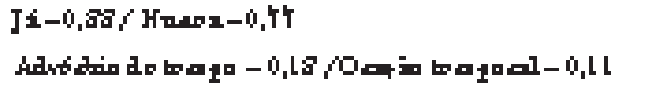 \\
\hline 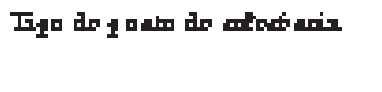 & 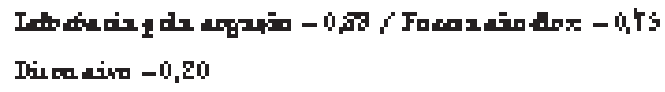 \\
\hline 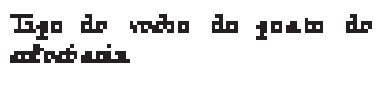 & 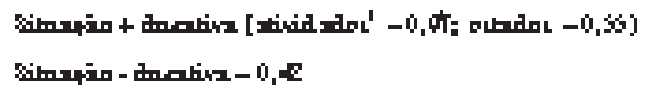 \\
\hline 8tibarix a a thlogim & 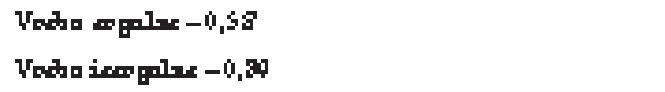 \\
\hline 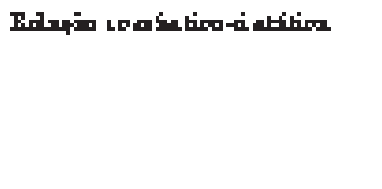 & 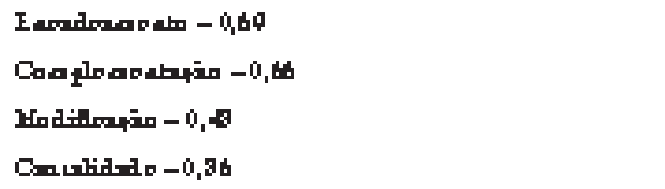 \\
\hline Arasiadade & 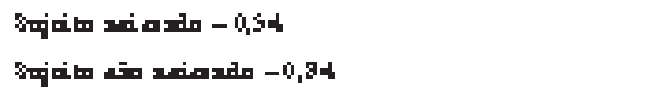 \\
\hline
\end{tabular}

ples a partir dos resultados obtidos na análise de grupos de fatores linguísticos

\footnotetext{
${ }^{5}$ Pesos relativos superiores a 0,50 favorecem a aplicação da regra; se forem inferiores a 0,50 , inibem a aplicação da regra.

${ }^{6}$ De acordo com Vendler (1967, p. 106), atividades não precisam de um término, sendo verdadeiras mesmo quando interrompidas. Verbos de atividade não co-ocorrem com advérbios do tipo em uma hora, somente com advérbios durativos (durante uma hora). Uma pergunta apropriada para considerar uma situação como atividade é aquela que evidencia uma duração no tempo: "Por quanto tempo...".
} 
A utilização do pretérito mais-que-perfeito paralela a formas de imperfeito (peso relativo de 0,67 ) justifica-se pelo paralelismo (marcas levam a marcas: pretérito imperfeito > pretérito mais-que-perfeito composto com o verbo ter no imperfeito - tinha). A baixa ocorrência, por outro lado, do pretérito perfeito, igualmente, comprova o paralelismo (pretérito perfeito leva ao pretérito perfeito) - 0,39.

Situações dinâmicas (peso relativo de 0,63) condicionam o aparecimento do pretérito mais-que-perfeito. Possivelmente, requerem uma forma de codificação marcada, já que são mais salientes por conduzirem a sequência de ações, normalmente em figura ${ }^{7}$, no fluxo discursivo. Por outro lado, situações menos dinâmicas desfavorecem o pretérito mais-que-perfeito $(0,29)$. Isso, em princípio, justifica-se porque os estados não são salientes do ponto de vista perceptual e, normalmente, correspondem à informação de fundo na cadeia discursiva.

$\mathrm{O}$ advérbio já favorece o pretérito mais-que-perfeito $(0,88)$. Parece que, em Português, há uma forte tendência em associar o advérbio já ao pretérito mais-que-perfeito; um leva ao outro. Talvez, seja possível falar em especialização de uso em direção a um processo de gramaticalização decorrente da recorrência de certas construções. Tudo indica que o pretérito mais-que-perfeito está perdendo sua característica própria de anterioridade, sendo, então, necessária a presença do advérbio já. O advérbio de negação nunca $(0,77)$ pode negar todo o período passado, não apenas um período no passado. Associar o advérbio nunca ao pretérito mais-que-perfeito implica marcar a terminação dessa situação antes de outro tempo passado. O peso relativo atribuído aos advérbios temporais (0,18 em relação ao pretérito mais-que-perfeito) indica que tais expressões favorecem o pretérito perfeito, o que se justifica pela não necessidade de marcar uma situação já marcada temporalmente; isso se aplica, também, aos casos de oração temporal $(0,11)$. A partir desta análise, é possível prever uma tendência de uso dos pretéritos mais-que-perfeito e perfeito. O pretérito mais-que-perfeito ocorre quando associado aos advérbios já e nunca; o pretérito perfeito quando associado a outros advérbios temporais.

Em relação ao tipo de ponto de referência, a 'inferência pela negação' (0,83) favorece o pretérito mais-que-perfeito (Nunca tinha visto isso.), possivelmente, por ser mais fácil processar a informação

\footnotetext{
${ }^{7}$ Koffka (1975) descreve o plano ambiental como duplamente organizado (figura/ fundo). A figura constitui o relevo, por isso, é percebida como mais saliente e o fundo aparece como suporte, caracterizando-se como neutro.
} 
na presença do pretérito mais-que-perfeito, já que o pretérito perfeito pode indicar, também, duração até o tempo de fala (Nunca vi isso.). O alto peso associado à 'presença de forma não-flexionada' $(0,75)$ deve ter ocorrido porque há, no ponto de referência, um tempo relativo (verbo no infinitivo ou no gerúndio). Assim, o processamento é facilitado quando a forma seguinte é um pretérito mais-que-perfeito. Os casos envolvendo ponto de referência discursivo $(0,02)$ retomam uma situação já mencionada que, por ser velha, não necessita ser marcada formalmente. Assim, o pretérito mais-que-perfeito é desfavorecido.

O pretérito mais-que-perfeito é favorecido, ainda, quando há verbo de atividade $(0,97)$ e estado $(0,55)$ no ponto de referência. Devido ao fato de estados e atividades possuírem um componente durativo, favorecem o aparecimento do pretérito mais-que-perfeito para que as dimensões temporais passadas, envolvendo dado variável e ponto de referência, estejam especificadas. A utilização, por outro lado, do pretérito perfeito poderia, à primeira vista, gerar interpretação de cotemporalidade. Note-se que o critério da extensão temporal parece dominar e determinar as escolhas. Se o ponto de referência é mais estendido, então predomina o pretérito mais-que-perfeito. Por outro lado, quando o ponto de referência é menos estendido no tempo, ocorre o pretérito perfeito. A ocorrência de 0,42 para situações menos durativas corresponde a nossa hipótese de que verbos desse tipo se inclinam a favorecer o pretérito perfeito por denotarem situações bem delimitadas temporalmente.

Os resultados sobre saliência não correspondem às hipóteses já que é o verbo regular que favorece o pretérito mais-que-perfeito $(0,58)$. Acreditamos que, nesse caso, os resultados talvez não se justifiquem pela saliência, mas pela interferência de outra variável: diferenciação entre ação/estado. Verbos de estado são, na maioria, irregulares (ser, estar, ter). Como favorecem o pretérito perfeito, devem influenciar no peso relativo associado ao verbo irregular $(0,39)$. Em termos percentuais, $63 \%$ dos verbos de estado são irregulares e $63 \%$ dos verbos dinâmicos são regulares. Assim, se verbos de estado desfavorecem o pretérito maisque-perfeito, verbos irregulares, por estarem fortemente correlacionados aos estativos, também tendem ao desfavorecimento. Por outro lado, a correlação entre situação dinâmica e verbo regular interfere na probabilidade de ocorrência de pretérito mais-que-perfeito.

O encadeamento discursivo $(0,69)$ favorece o uso do pretérito mais-que-perfeito por duas razões: evitar a interpretação de cotemporalidade e de sequencialidade. Duas situações justapostas, nas quais 
nenhuma relação circunstancial é percebida, podem evidenciar cotemporalidade, assim aparece o pretérito mais-que-perfeito para, de imediato, demonstrar a relação de anterioridade. O resultado associado à complementação $(0,66)$ justifica-se pelo fato de orações completivas serem mais comumente ensinadas como contextos prototípicos de ocorrência do pretérito mais-que-perfeito, o que pode ter sido relevante para esse resultado. Talvez, haja mais do que isso. A relação de complementação, normalmente, ocorre na presença de verbo dicendi ou verbo de estado, ambos favorecedores do pretérito mais-que-perfeito.

A modificação $(0,43)$ desfavorece o pretérito mais-que-perfeito porque, quando falamos sobre alguma situação modificada, essa modificação ocorreu antes do processo de enunciação do ponto de referência. Relação de efeito/causa $(0,36)$, também, desfavorece o pretérito mais-que-perfeito, já que efeito pressupõe causa. A relação pode ser assinalada pelo conector e/ou pelo próprio item lexical que demonstra qual é a causa que antecede o efeito evidenciado no discurso. Assim, o pretérito mais-que-perfeito não precisa entrar no enunciado como marcador da relação semântica.

Em relação ao tipo de sujeito, os resultados confirmam nossa crença. Por causa da animacidade envolvida, a situação tende a ocorrer no pretérito mais-que-perfeito ( 0,54 para animacidade versus 0,34 para não animacidade). Ainda, situações referentes a sujeitos mais animados parecem ter mais importância no fluxo da informação, no sentido de serem mais recorrentes e permanecerem por mais tempo. Sendo mais importantes, devem ser, naturalmente, mais salientes.

\section{Uso variável do pretérito imperfeito e da forma progressiva na expres- são do passado imperfectivo}

O pretérito imperfeito do indicativo (IMP) é uma forma verbal caracterizada pelas diferentes funções de tempo, aspecto e modalidade que pode codificar, em diferentes contextos. Aparentemente, o Português apresenta duas formas verbais para codificar o mesmo valor temporal-aspectual, o pretérito imperfeito (IMP) e o passado progressivo (PPROG), como as destacadas em (03) e (04):

(03) Na época que eu mais precisei dele, que eu mais PRECISAVA (IMP) de um apoio, foi quando a minha mãe morreu. (SC FLP 03)

(04) Aí também foi na época que a gente voltou, a gente estava precisando economizar pra começar nossa vida. (SC FLP 01) 
As formas são intercambiáveis quando assumem o valor semânticodiscursivo passado imperfectivo. O passado imperfectivo é uma função caracterizada temporalmente pela relação de ordenação e sobreposição e, aspectualmente, pela relação de inclusão. Em relação ao tempo, o passado imperfectivo refere-se a uma situação anterior ao momento de fala e simultânea ao ponto de referência, também anterior, daí a noção de passado. Em relação ao aspecto, o passado imperfectivo

\begin{tabular}{|c|c|}
\hline 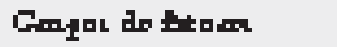 & 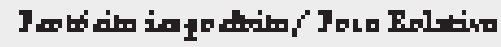 \\
\hline 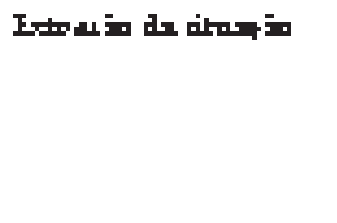 & 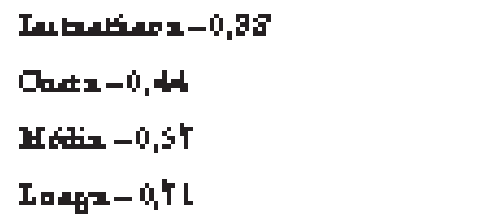 \\
\hline 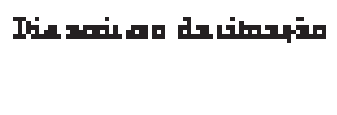 & 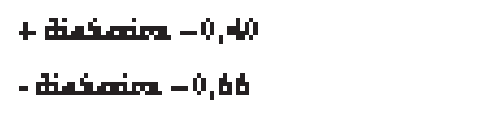 \\
\hline Autata & 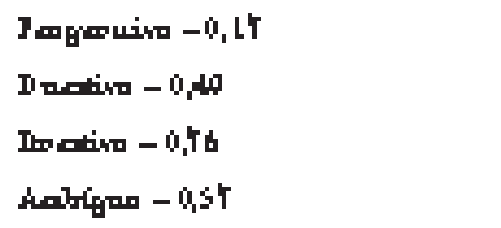 \\
\hline ralin & 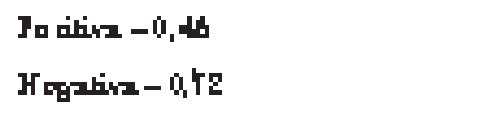 \\
\hline 殒口 & 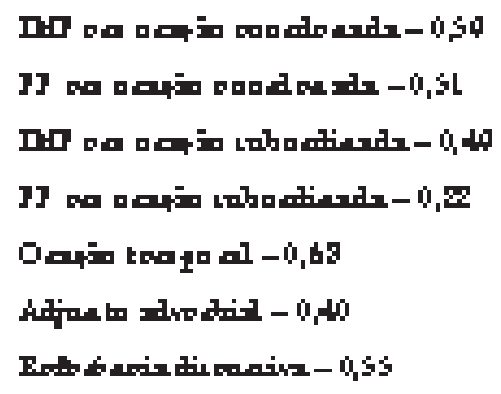 \\
\hline Fingrting & 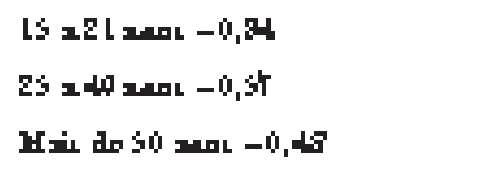 \\
\hline
\end{tabular}

a partir dos resultados obtidos na análise de grupos de fatores linguísticos 
refere-se a uma situação cujo intervalo inclui o ponto de referência, o que manifesta o andamento da situação em relação à referência, daí a noção de imperfectividade. As formas desempenham a mesma função semântico-discursiva, funcionando como variantes de uma mesma variável linguística. Entretanto, cada forma tem contextos de recorrência específicos. Foram analisadas 882 ocorrências de passado imperfectivo, das quais 546 são realizadas pela forma IMP (valor de aplicação).

O Português não apresenta um sistema gramaticalizado (no sentido de pertencer à gramática da língua) de extensão/duração de uma situação. Para codificar esse tipo de informação, fazemos uso de recursos lexicais, como advérbios e nomes que denotem extensão ou duração temporal. ${ }^{8}$ Na expressão do passado imperfectivo, o peso relativo de 0,38 restringe o uso de IMP em intervalos classificados como instantâneos, enquanto o peso relativo de 0,71 favorece seu uso em intervalos temporais classificados como muito longos. A distribuição dos

${ }^{8}$ A extensão da situação foi uma variável controlada por Mendes (2005) para averiguar
a variação entre ter + particípio e estar + gerúndio na expressão dos aspectos durativo
e iterativo no Português. O autor estabeleceu uma classificação para a extensão do
intervalo de tempo circunscrito pelo aspecto: tempo curto, tempo longo e tempo muito
longo. Para dar conta da expressão do passado imperfectivo, a classificação de Mendes
(2005) foi ampliada, pois os valores aspectuais envolvidos são diferentes. No aspecto
progressivo, por exemplo, a situação é vista em seu desenvolvimento a partir de um
único ponto temporal, que não necessariamente perfaz dias ou semanas; pode-se
pensar em tempo quase instantâneo, medido em minutos ou horas. O mesmo vale
para o aspecto durativo e iterativo, e também para as situações aspectualmente
ambíguas. Assim, a classificação adaptada conta com quatro possibilidades para a
extensão do intervalo temporal: instantâneo, curto, longo e muito longo: Tempo instantâneo

[em termos de minutos, horas] Daí a moça tinha ido para o hospital e o cara morreu. Daí a gente, a hora que a gente estava olhando, eles tiravam o cara morto ainda. (SC FLP FGJ 07)

Tempo curto

[em termos de dias, semanas] Fui [posto] na rua da aula de história, de química, de ciências, mas também aprontava pra caramba. De ciências eu fui umas três vezes, de história eu cheguei a ser suspenso da aula dele, uma semana, é, eu parei de fazer barulho, fui obrigado, né? Fui suspenso, só estava pegando no meu pé. (SC FLP MCJ 13)

Tempo longo

[em termos de meses] Agora até que a gente estava lendo, só que no começo do ano a gente estava lendo bastante. (SC FLP FGJ 07)

$\mathrm{Eu}$, não, é que eu tinha, eu estudava no Aplicação e deu um rolo ali com um cara ali, professora me chamou atenção e chamou meus pais, tudo, que eu ia ser expulso do colégio, tal, e não sei mais o que. (SCFLP MJP 09)

Tempo muito longo

[em termos de anos] Dizem que ela estava bem doente. É, foi o ano passado, o meu irmão esteve aqui, ele entrou de férias e veio passar uns dias aqui em casa, porque ele mora no Rio, né? e ele falou que ela estava morando pra cá. Tinha vendido, parece, uma casa lá no Rio e veio morar pra cá. (SC FLP FAP 03) 
resultados é crescente: intervalos temporais classificados como curtos têm peso relativo de 0,44 , enquanto intervalos temporais classificados como longos têm peso relativo de 0,57. Assim, na expressão do passado imperfectivo, as formas IMP e PPROG se diferenciam quanto ao uso em função da extensão temporal, possivelmente por efeitos da origem das formas: PPROG está relacionado com a expressão de aspecto progressivo, que toma a situação em andamento em relação a um ponto temporal (ponto de referência), propriedade que pode persistir no processo de gramaticalização e generalização semântica da forma, com a associação de PPROG a tempo instantâneo/curto; IMP está relacionado ao deslocamento/distanciamento da realidade, também evocando a persistência, pode ser associado a tempo longo.

No domínio da imperfectividade, assumindo a proposta de Comrie (1976), o passado imperfectivo recobre valores que vão desde o progressivo até o habitual, passando pelo durativo, iterativo e por casos de ambiguidade aspectual (imperfectivo genérico, valor em que a especificidade aspectual não é não relevante nem para o falante nem para o ouvinte), em uma escala aspectual, do sentido mais estrito ao mais amplo (progressivo $>$ durativo $>$ iterativo $>$ ambiguo). Os valores extremos da escala aspectual - progressivo e iterativo - mostram-se fortemente correlacionados com uma forma para sua expressão. O imperfectivo progressivo associa-se à forma PPROG, com peso relativo de 0,83, ao passo que o imperfectivo iterativo associa-se à forma IMP, com peso relativo de 0,76 .

Também o dinamismo das situações indica tendências opostas para a expressão do passado imperfectivo. Em situações [+ dinâmicas], a forma PPROG é favorecida, com peso relativo entre 0,60 (0,40 para IMP) e 0,64 (0,36 para IMP), enquanto em situações [- dinâmicas], a forma IMP é favorecida, com pesos relativos oscilando entre 0,66 (0,34 para PPROG) e 0,60 (0,40 para PPROG). Esta polarização pode ser vista como efeito do processo de gramaticalização da forma estar + Vndo e que persiste na trajetória da forma PPROG. Hopper (1991, p. 24), ao propor princípios da gramaticalização, fala da persistência: "quando uma forma sofre gramaticalização passando de lexical a gramatical, alguns traços de seu sentido lexical original tendem a continuar, e detalhes da sua história lexical podem refletir no condicionamento da sua distribuição gramatical”. É o que está acontecendo com PPROG: um detalhe da sua história gramatical (quando funcionava como progressivo estrito) tem reflexo na sua distribuição nos contextos em que a forma já gramaticalizou o valor de passado imperfectivo. 
Considerando o princípio da marcação (Givón, 1995), o critério da complexidade estrutural pressupõe que a oração negativa é marcada em relação à afirmativa, e considerando também que na expressão do passado imperfectivo há uma forma estruturalmente mais marcada (PPROG) do que a outra (IMP), como se dá a interação entre formas e negação em função do critério da marcação? Contextos marcados (com presença de negação) tendem a atrair formas marcadas? Ou contextos marcados tendem a atrair formas não-marcadas? A análise aponta que contextos de oração afirmativa tendem a favorecer a ocorrência da forma mais complexa, PPROG, enquanto contextos de oração negativa tendem a favorecer a ocorrência da forma menos complexa, IMP; forma marcada tende a ser utilizada em contexto menos marcado e forma não-marcada é preferível em contexto marcado (Gorski; Tavares; Freitag, 2008).

Quando o ponto de referência para o passado imperfectivo é discursivo, a escolha das formas não parece ser influenciada; uma leve tendência à forma IMP é apontada pelo peso relativo oscilando de 0,55. Os fatores que favorecem a ocorrência de IMP para expressar passado imperfectivo são oração temporal e IMP em período composto por coordenação, ambos com pesos relativos na casa de 0,60. Já PPROG é fortemente favorecido em contextos de $\mathrm{PP}$ em período composto por subordinação, com peso relativo de 0,78 (0,22 para IMP), e também em contextos de adjunto adverbial, com pesos relativos na casa de 0,60 $(0,40$ para IMP).

Socialmente, a variação na expressão do passado imperfectivo está relacionada com a gradação etária dos informantes. Há uma forte correlação entre o uso de PPROG e a faixa etária mais jovem, em oposição às faixas mais velhas, que apresentam um comportamento estatisticamente mais próximo.

\section{Considerações finais}

Considerando os resultados quantitativos obtidos, diagramamos os contextos discursivos preferenciais para o uso das formas verbais analisadas, distribuindo os fatores condicionantes em uma linha que relaciona o ponto de referência à situação.

a) Pretérito mais-que-perfeito composto 


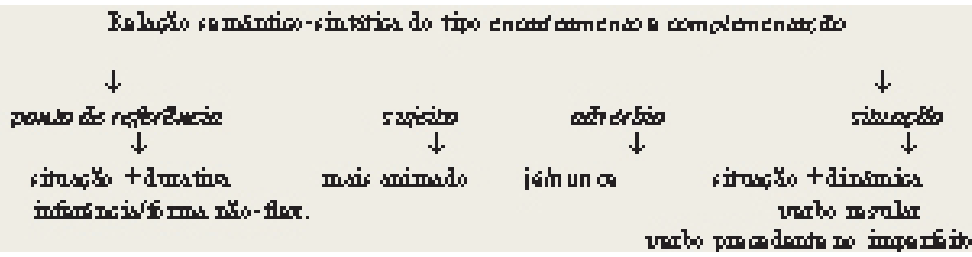

b) Pretérito perfeito simples

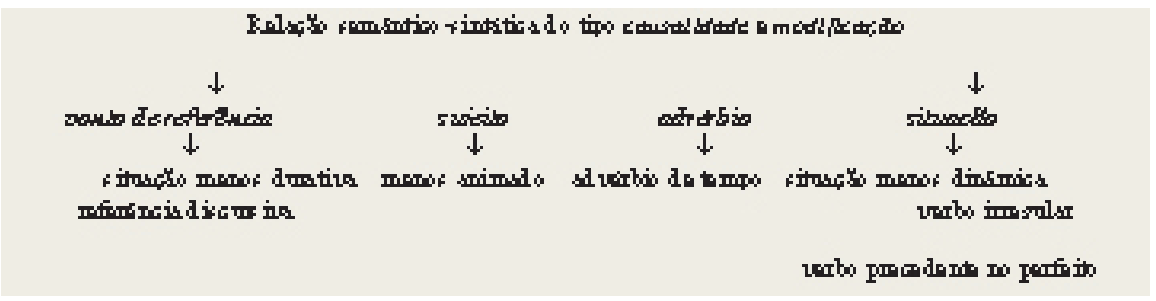

Em relação à situação, quando é mais dinâmica, favorece o aparecimento do pretérito mais-que-perfeito, preferencialmente com formas verbais regulares, com a presença dos advérbios já e nunca e com formas de pretérito imperfeito precedentes. Por outro lado, quando a situação é menos dinâmica, codificada por verbo irregular, associada a advérbio temporal e precedida de formas no pretérito perfeito, aparece o pretérito perfeito para indicar o passado anterior. Quando o ponto de referência apresenta o traço mais durativo e é codificado por uma forma que indica tempo relativo, aparece o pretérito mais-que-perfeito para delimitar a anterioridade da situação em relação a seu ponto de referência, por natureza estendido. Por outro lado, ponto de referência menos durativo é temporalmente delimitado, logo, não há necessidade de marcar a situação, assim o pretérito perfeito tende a ocorrer. Entre dado variável e ponto de referência, as relações semântico-sintáticas de encadeamento $e$ complementação favorecem o aparecimento do pretérito mais-que-perfeito. Já relações do tipo modificação e causalidade favorecem o pretérito perfeito.

c) Pretérito imperfeito simples (IMP)

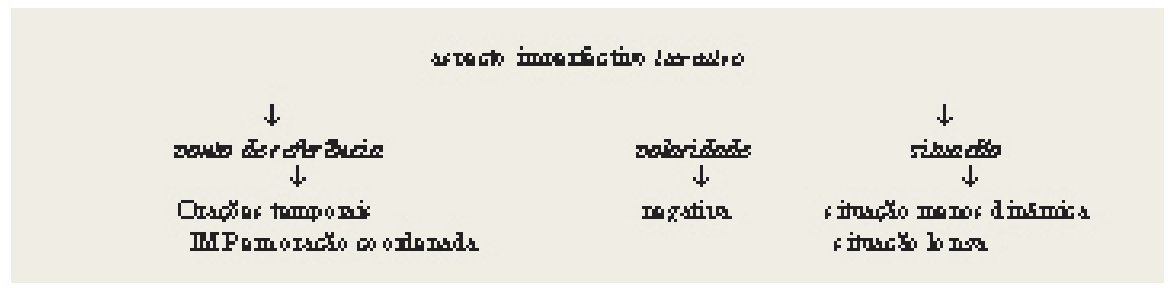


d) Pretérito imperfeito perifrástico (PPROG)

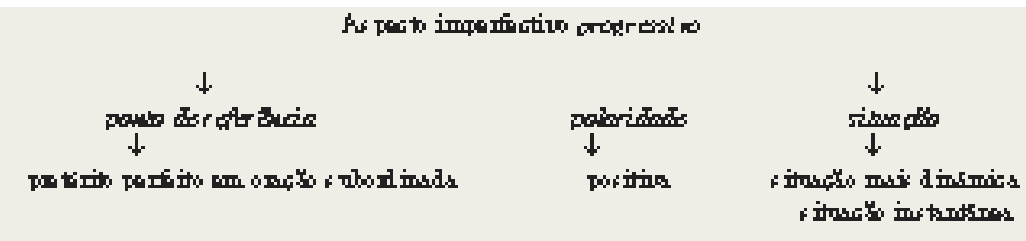

Grosso modo, a torma IMP está relacionada à expressao dos aspectos habitual e iterativo, predicados [- dinâmicos], situações longas, de polaridade negativa; já a forma PPROG está relacionada à expressão do aspecto progressivo, predicados [+ dinâmicos], situações instantâneas e curtas, de polaridade positiva.

Com esta análise, mostramos que a escolha de uma ou outra forma verbal para expressar o mesmo valor semântico-discursivo deve-se a "motivações em competição", que vão desde um nível que podemos denominar de semântico-cognitivo, baseado na percepção de acontecimentos do mundo real, passando por um nível mais facilmente captado na codificação linguística, seja por relações de significação estabelecidas via conectores sintáticos, seja por traços de significação inerentes aos itens lexicais, até chegar a um nível essencialmente associado à codificação morfossintática, situando-se o fenômeno investigado em um domínio funcional complexo.

Os pressupostos teórico-metodológicos da Sociolinguística Variacionista conduziram-nos a estudos empíricos, possibilitando o conhecimento e a sistematização de usos linguísticos. Em consonância com os Parâmetros Curriculares Nacionais (Brasil, 1998), os estudos variacionistas desencadearam propostas de ensino assentadas na ampliação da competência linguística do aluno, à medida que se ampliam os papéis sociais. Dentre os objetivos listados para o ensino de Língua Portuguesa, nos PCNs, destacamos: ampliar o domínio ativo do discurso, nas diversas situações sociais, por meio de atividades que envolvam variação linguística. Ao invés de os tempos verbais do passado serem ensinados e exemplificados mediante paradigmas de conjugação, a análise variacionista, partindo de contextos reais de uso, permite que se delineiem as configurações semântico cognitivas e morfossintáticas que favorecem a escolha de uma ou de outra forma, subsidiando, assim, um ensino de língua materna - e de Português como língua estrangeira - mais focado com objetivos definidos nos PCNs (Brasil, 1998).

Nossa pesquisa, empreendida no âmbito da Sociolinguística, embora siga o viés da descrição e da análise linguística, incita o desenvolvimento de políticas de ensino de língua que incorporem os resultados de pesquisas empreendidas pela Sociolinguística, por exemplo, 
para demonstrar que é preciso ensinar a ler formas multifuncionais e em variação. Considerando-se os processos de variação e mudança envolvendo categorias verbais, a não incorporação desses ao ensino de Língua Portuguesa desencadeia problemas de leitura e interpretação, devido à ampliação ou redução ou alteração de significado e devido à variação de formas competindo para codificar uma mesma função.

\section{Referências bibliográficas}

ALMEIDA, Napoleão Mendes de. Gramática metódica da Língua Portuguesa. São Paulo: Saraiva, 1982.

BRASIL. Secretaria de Educação Fundamental. Parâmetros Curriculares Nacionais: terceiro e quarto ciclos do ensino fundamental: Lingua Portuguesa/ Secretaria de Educação Fundamental. Brasília: MEC/SEF, 1998.

COAN, Márluce. Anterioridade a um ponto de referência passado: pretérito (mais-que-) perfeito. 1997. Dissertação (Mestrado em Linguística) Curso de Pós-graduação em Linguística, Universidade Federal de Santa Catarina, Florianópolis.

; BACK, Angela; REIS, Mariléia Silva; FREITAG, Raquel Meister Ko. As categorias verbais tempo, aspecto, modalidade e referência: pressupostos teóricos para uma análise semântico-discursiva. Estudos Linguísticos, v. XXXV, p. 1463-1472, 2006.

COMRIE, Bernard. Tense 4 ed. Cambridge: Cambridge University Press, 1990. Aspect. Cambridge: Cambridge University Press, 1976.

CUNHA, Celso; CINTRA, Lindley. Nova Gramática do Português Contemporâneo. 3 ed. Rio de Janeiro: Nova Fronteira, 2001.

FREITAG, Raquel Meister Ko. A expressão do passado imperfectivo no português: variação/gramaticalização e mudança. 2007. Tese (Doutorado em Linguística). Programa de Pós-graduação em Linguística da Universidade Federal de Santa Catarina, Florianópolis, 2007.

GIVÓN, Talmy. Tense-Aspect-Modality. In: Syntax: a functional-typological introduction. Vol 1, Amsterdam/Philadelphia: J. Benjamins, 1984.

. Functionalism and grammar. Amsterdam/ Philadelphia: John Benjamins Publishing, 1995.

GORSKI, Edair; TAVARES, Maria Alice; FREITAG, Raquel Meister Ko. Restrições de natureza cognitivo-comunicativa: marcação vs. expressividade retórica em fenômenos variáveis. In: Claudia Roncarati; Jussara 
Abraçado. (Org.). Português brasileiro II: contato linguístico, heterogeneidade e história. Niterói: EdUFF, 2008, v. 2, p. 101-117.

HOPPER, Paul. On some principles in the grammaticalization. In: E. Traugott, B. Heine (eds.). Approaches to grammaticalization. Philadelphia: John Benjamins Company, 1991. v. 1. p. 17-35

KOFFKA, Kurt. Princípios da psicologia da Gestalt. São Paulo: Cultrix, 1975.

LABOV, William. Principles of linguistic change: internal factors. Oxford: Blackwell, 1994.

. Principles of linguistic change. social factors. Oxford: Blackwell, 2001. . Sociolinguistics patterns. Pennsylvania: University of Pennsylvania Press, 1972. . Where does the linguistic variable stop? A response to Beatriz Lavandera. In: Sociolinguistics Working Paper. Austin: Southweast Educational Development Laboratory, n. 44, 1978. p. 43-88

LUFT, Celso. Pedro. Gramática resumida. Porto Alegre: Editora Globo, 1976.

MENDES, Ronald Beline. Estar + gerúndio e ter + particípio: aspecto verbal e variação no português. Tese (Doutorado em Linguística) - Programa de Pós-Graduação em Estudos da Linguagem da Universidade Estadual de Campinas, 2005.

NUNES, José Joaquim. Gramática histórica portuguesa. 9 ed. Lisboa: Editora Clássica, 1989.

PEREIRA, Eduardo Carlos. Gramática histórica. São Paulo: Editora Monteiro Lobato \& Cia, 1923.

REICHENBACH, Hans. The tenses of verbs. Elements of symbolic logic. New York: The Macmillan Company, 1947.

ROCHA LIMA, Gramática Normativa da Lingua Portuguesa. Rio de Janeiro: José Olympio, 1986.

RODRIGUES, Angela; CAMPOS, Odete; GALEMBEK, Paulo de Tarso; TRAVAGLIA, Luiz Carlos. Formas de pretérito perfeito e imperfeito do indicativo no plano textual-discursivo. In: Ingedore Koch (org.) Gramática do português falado - desenvolvimentos. Campinas: Editora da Unicamp, 1996. p. 415-461.

SAID ALI, Manoel. Gramática secundária e gramática histórica da Língua Portuguesa. São Paulo: Editora Universidade de Brasília, 1964.

VENDLER, Zeno. Verbs and Times. Linguistics and Philosophy. Ithaca, New York: Cornell University Press, 1967. 


\title{
Resumo
}

Neste texto, mostramos resultados de estudos variacionistas sobre o funcionamento da expressão do tempo passado, especificamente, quanto aos usos do pretérito perfeito vs. pretérito mais-que-perfeito composto e do pretérito imperfeito vs. forma progressiva do pretérito imperfeito, no Português. Inicialmente, apresentamos o domínio funcional complexo tempo-aspectomodalidade. No segundo momento, apresentamos o funcionamento variável dos pretéritos sob análise. Ao final, tecemos considerações acerca da implicação da diversidade de usos das formas verbais de passado no ensino de Língua Portuguesa.

Palavras-chave: categorias verbais; passado anterior; passado imperfectivo; variação; ensino de Língua Portuguesa.

\begin{abstract}
In this text, variation studies about the past tense functions in Portuguese are presented, specifically the uses of "pretérito perfeito" vs. "pretérito maisque-perfeito composto" and "pretérito imperfeito" vs. "forma progressiva do pretérito imperfeito". First, the complex functional domain tense-aspect-modality is presented. After, the variable uses of the preterits analyzed are presented. At the end, this text discusses the diversity of uses of the verbal forms analyzed in Portuguese teaching.
\end{abstract}

Key words: verbal categories; anterior past; imperfective past; variation; Portuguese teaching. 